\title{
Efficiency of application of fiber concrete as a material for manufacturing bodies of centrifugal pumps
}

\author{
Kassym Yelemessov ${ }^{1}$, Dilda Nauryzbayeva $^{1}$, Saiyn Bortebayev $^{1}$, Dinara Baskanbayeva $^{1,}{ }^{*}$, and Viktoriya Chubenko $^{2}$ \\ ${ }^{1}$ Satbayev University, 22 Satpayev Str., 050013, Almaty, the Republic of Kazakhstan \\ ${ }^{2}$ Krryvyi Rih National University, Ferrous metals metallurgy \& foundry Department, 11 Vitalii Matusevysch Str., Kryvyi Rih, 50027, \\ Ukraine
}

\begin{abstract}
The report presents the results of research on the use of composite material - fiber-reinforced concrete for the manufacture of centrifugal pump bodies. The, optimal composition of fiber-reinforced concrete with the required strength characteristics has been established. The method of casting a pump body and the results of industrial tests to determine the technological parameters of a centrifugal pump are presented. The results obtained showed that fiber-reinforced concrete bodies have an advantage over metal ones and can be recommended for use in mechanical engineering in the manufacture of centrifugal pump bodies.
\end{abstract}

\section{Introduction}

In the process of the development of the mining and metallurgical and oil and gas industries, the requirements for the quality of the products were increased, as well as the environmental and safety requirements for equipment became more stringent.

All these factors led to the emergence of new technologies for processing raw materials, the technological parameters of the equipment began to change, and new chemical liquids, more aggressive not only with respect to the material being processed, but also to the working bodies of the equipment, began to be used in technological processes.

This caused the following problems when operating the pumping equipment:

- the appearance of corrosion and erosion of pump elements in direct contact with the pumped corrosive liquid;

- the presence of solid inclusions in the pumped liquid led to abrasive wear of the pump flow path;

- as follows from the above, during the operation of the pumps, there is the appearance of hydraulic shocks during the operation of the pump and an increase in wear of the housing elements, which led to thinning of the housing walls, as well as an increase in vibration of the entire unit and a reduction in the service life of the bearings due to the growth of cavitation processes.

Based on the analysis of the main problems of the operation of pumping units, standards for the manufacture of pumping units were developed, which made it possible to unify the requirements for equipment and bring reliability indicators to a single denominator $[1,2]$.

Modern standards rather strictly regulate the types of materials, depending on the types of pumping equipment used. Pump elements that have direct contact with an aggressive liquid are practically not made of gray cast iron, since it is not resistant to aggressive liquids, as a result of which there is a rapid destruction of metal and frequent replacement of elements is required, which worsens the reliability of the pump and increases operating costs [3, 4]. For pumping corrosive liquids, materials with the required strength and resistance against corrosion and erosion are used, as well as special alloys that can withstand high temperatures of the pumping liquid. For example, high-alloy chromium-nickel steel is used for pumping acidic liquids. Depending on the discharge pressure, the properties of the pumped material and its aggressiveness, carbon steels and aluminum alloys are also used. Practice shows that with an increase in wall thickness, porosity forms in cast iron bodies. In this regard, the bodies are cast from carbon alloys. Considering the dimensions and weight of the pumping equipment of the mining and processing enterprise, then considerable funds are spent on casting the pump body $[5,6]$.

One of the ways out of this situation is the use of construction materials with a low cost, but meeting the requirements of the conditions for the safe operation of equipment. This material includes fiber concrete.

Fiber concrete is a fine-grained material, one of which is a reinforcing filler. These composites are very promising for use in mechanical engineering, in particular, in the manufacture of body parts for pumping equipment [7].

Modernization of centrifugal pump casings by replacing materials with composite materials is very important.

Currently, fiber-reinforced concretes are widely used in the production of building materials and have been

\footnotetext{
${ }^{*}$ Corresponding author: baskanbaeva@mail.ru
} 
thoroughly investigated. However, there are practically no works related to the study of the use of these materials in mechanical engineering, especially for the manufacture of parts of technological equipment [8-10].

Research work on the use of fiber-reinforced concrete as a material for the manufacture of centrifugal pump casings was carried out at the Kazakh National Research Technical University named after K.I. Satpayev. These studies were carried out in a wide range from the selection of a rational composition of fiber-reinforced concrete to testing a cast body sample in an industrial environment. This article presents the main results of these researches.

\section{Methods}

To create a composite material, theoretical and experimental studies were carried out. Theoretical studies included a patent-literature review on composite materials, including fiber-reinforced concrete, as well as on existing methods of mixture preparation and casting technology for body parts. In experimental studies, the optimal composition of the mixture was determined, the mechanical properties of fiber-reinforced concrete were tested [5], the casting technology of the body was worked out and the industrial test of the finished body made of fiber-reinforced concrete was carried out. To conduct an experimental study, a method was developed for determining the mechanical properties of fiber-reinforced concrete and a method for conducting tests on an industrial bench in the conditions of JSC "Almaty Heavy Engineering Plant". The results of experimental studies were processed according to the standard method of mathematical statistics. Based on the research results, a comparative assessment of pump casings made of fiberreinforced concrete and metal is given.

This composition of polymer concrete is selected based on a number of requirements.

1. The need to obtain a mixture with a mobility of $8 \ldots$ $9 \mathrm{~cm}$, which should provide a good filling of the die for casting the product-the gearbox housing or the centrifugal pump snail.

2. The need to ensure the strength of polymer concrete in order to withstand the statistical and dynamic loads of the tested products.

The sequence of the researches carried out made it possible to obtain a composite material with the required strength characteristics by simple technology and low cost.

\section{Results and discussion}

The conducted research has established the optimal composition of fiber-reinforced concrete, consisting of granite gravel, quartz sand, quartz flour with the addition of steel fiber. Epoxy resin was used as a binder (table 1).

From the investigated composition of fiber-reinforced concrete, the 1st composition with steel fiber was selected, which made it possible to obtain a composite material that fully meets the requirements for the material for the manufacture of centrifugal pump bodies.

For the casting of the centrifugal pump body that meets the necessary requirements, special researches were carried out, which made it possible to work out the technology of manufacturing casting matrices and fiberreinforced concrete mixtures with the development of casting technology.

Table 1. The investigated compositions of fiber-reinforced concrete.

\begin{tabular}{|c|c|c|c|c|c|c|c|}
\hline \multirow[b]{2}{*}{ № } & \multirow[b]{2}{*}{ Components } & \multicolumn{2}{|c|}{$\begin{array}{c}\text { Composition } \\
1 \\
\end{array}$} & \multicolumn{2}{|c|}{\begin{tabular}{|c|} 
Composition \\
2
\end{tabular}} & \multicolumn{2}{|c|}{\begin{tabular}{|c} 
Composition \\
3
\end{tabular}} \\
\hline & & $\begin{array}{l}\text { Con- } \\
\text { sum- } \\
\text { ption } \\
\text { in \% }\end{array}$ & \begin{tabular}{|c|} 
Con- \\
sum- \\
ption \\
in \\
grams
\end{tabular} & $\begin{array}{l}\text { Con- } \\
\text { sum- } \\
\text { ption } \\
\text { in \% }\end{array}$ & $\begin{array}{l}\text { Con- } \\
\text { sum- } \\
\text { ption } \\
\text { in } \\
\text { grams }\end{array}$ & $\begin{array}{l}\text { Con- } \\
\text { sum- } \\
\text { ption } \\
\text { in \% }\end{array}$ & $\begin{array}{l}\text { Con- } \\
\text { sum- } \\
\text { ption } \\
\text { in } \\
\text { grams }\end{array}$ \\
\hline 1 & $\begin{array}{l}\text { Granite } \\
\text { gravel }\end{array}$ & 51 & 1000,0 & 52 & 1040,0 & - & - \\
\hline 2 & Rubble & - & - & - & & 51 & 1000,0 \\
\hline 3 & Quartz sand & 25,5 & 502,0 & - & - & 25,5 & 502,0 \\
\hline 4 & Quartz flour & 11 & 220,0 & - & - & 11 & 220,0 \\
\hline 5 & \begin{tabular}{|l} 
Andesite \\
flour \\
\end{tabular} & - & - & 33.6 & 620,0 & - & - \\
\hline 6 & Fiber: & & & & & & \\
\hline 6.1 & Steel wire & $3,5^{*}$ & $70^{*}$ & - & - & - & - \\
\hline 6.2 & Fiberglass & - & - & $3,5^{*}$ & $70 *$ & - & - \\
\hline 6.3 & $\begin{array}{l}\text { Steel anchor } \\
\text { type }\end{array}$ & - & - & - & - & $3,5^{*}$ & $70^{*}$ \\
\hline 7 & Resin & 10,6 & 200,0 & 12 & 240,0 & 10,6 & 200,0 \\
\hline 8 & Hardener & 2,0 & 40,0 & 2,4 & 50.0 & 2,0 & 10,0 \\
\hline
\end{tabular}

Note: * . " \pm " to the total mass

The technological process of forming elements of centrifugal pump casings consists of the following operations:

- matrix and mold lubrication;

- installation of reinforcing cages;

- laying the fiber-reinforced concrete mixture into a matrix (form);

- molding of body parts;

- removal of finished products;

- drying of finished products.

The carried out analysis found that the most influencing factors on the strength characteristics in the preparation of fiber-reinforced concrete should be considered strict adherence to the technology of preparation of raw materials and the mixing mode of components, as well as the content of fiber. It was found that the dosage of the components of fiber-reinforced concrete should be carried out with an accuracy of $\pm 2 \%$ by weight. This mode of preparation of a fiber-reinforced concrete mixture makes it possible to obtain a homogeneous mixture with an even distribution of all components in its volume. This provides an isotropic solidified mixture with the same characteristics at any point. The analysis of the research results of the factors affecting the strength of fiber-reinforced concrete showed that the optimal time for mixing the components of the mixture for its strength is 5 ... 6 minutes at a working body rotation frequency of $800 \ldots 1000 \mathrm{rpm}$.

According to the results of the experiments, it was found that the most rational is the following composition of fiber-reinforced concrete (by volume): granite crushed stone $50 \ldots 52 \%$, quartz sand $25 \ldots 26 \%$, quartz flour $11 \%$, steel anchor-type fiber 3-4\%, epoxy resin 10-11\%, hardener $2 \%$. Such composition of fiber-reinforced 
concrete has a density of $2200 \ldots 2300 \mathrm{~kg} / \mathrm{m} 3$, compressive strength $230 \ldots 240 \mathrm{MPa}$, bending strength $80 \ldots 100 \mathrm{MPa}$.

Figure 1 shows the finished body of a standard centrifugal pump 1 K 20/30, cast from fiber-reinforced concrete.

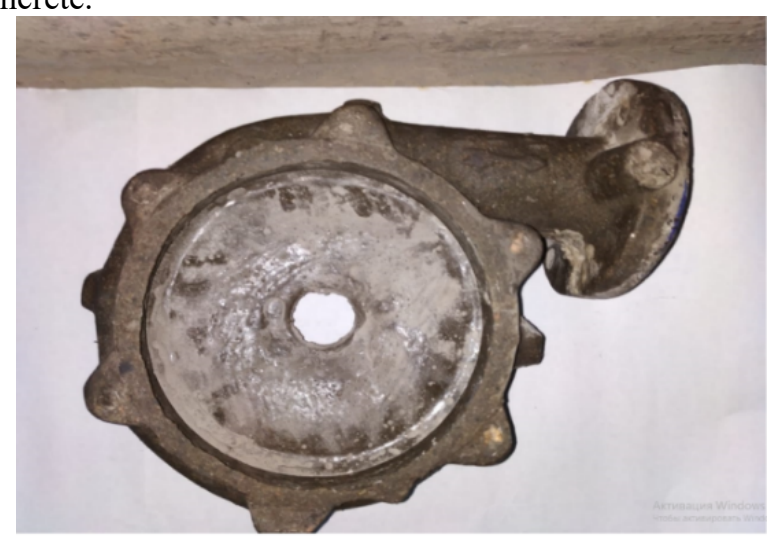

Fig. 1. Finished body of a centrifugal pump.

The cast samples and the results of the performed experiments on mechanical tests were presented to the specialists of the quality department and the management group of JSC AZTM for external evaluation of the obtained semi-industrial sample from fiber-reinforced concrete. Experts carried out visual-optical control in order to identify surface defects that could arise during installation and operation.

Visual-optical control was carried out before instrumental and non-destructive control methods. All measurements were made after visual control or simultaneously with it.

During visual-optical control, the following were checked:

- completeness of the pump;

- quality of protective coatings and colors;

- the presence of defects that affect the performance of the pump.

At the same time, special attention was paid to the presence of defects posing a possible danger of subsequent destruction of a part or assembly unit, such as:

- local mechanical damage (tears, kinks, dents);

- stratification of the base material;

- sunsets of the main material;

- deformation of parts and assembly units;

- defects of threads;

- cracks in the base material;

After casting, the halves of the body were glued together with an epoxy compound thickened with adhesive flour, and treated with an abrasive wheel. The glued body in 2 layers is covered with a gelcoat to reduce the roughness of the body surface.

For industrial testing, a $1 \mathrm{k} 20 / 30$ pumping unit with a fiber-reinforced concrete casing is connected to a test bench in the conditions of JSC "AZTM".

The test bench is designed for testing centrifugal pumps. At the test bench, it is possible to conduct research on individual devices used in the automation of a technological process and the following can be determined: (LS);
- characteristics of the electromagnetic relay;

- performance characteristics of the centrifugal pump;

- liquid consumption in various ways;

- study the device of the pressure switch and devices for measuring temperature and pressure, determine the thresholds for the pressure switch, measure temperature and pressure.

Evaluation of the effectiveness of the test bench is based on the registration of the parameters of a centrifugal pump in conditions close to production.

Modules of hydraulic and electrical control, which are structurally complete devices, are designed to control, measure the recorded values and monitor the work of the test bench.

Figure 2 shows the hydraulic diagram of the stand. All devices are installed in the body of the hydraulic control module, which are shown on the hydraulic diagram inside a rectangle highlighted by a dash-dot line. These are the following devices:

- CV - check valve;

- PS - pressure switch:

- V1 ... V5 - valves;

- WC - simulator of water consumers;

- T - temperature sensor;

- FM - flow meter;

- MN - manometer.

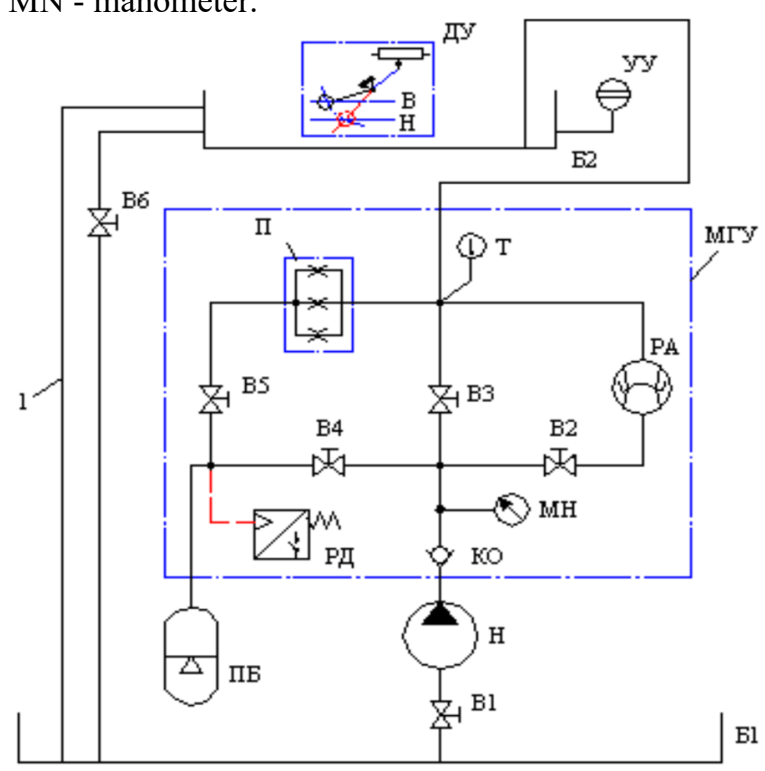

Fig. 2. Hydraulic diagram of the test bench.

In the electrical diagram of the test bench it is indicated (Figure 3):

- IS - potentiometric level sensor (installed in the upper hydraulic tank, pos. 6 in Figure 2);

- EMR - electromagnetic relay;

- PS - pressure switch (installed in the housing of the hydraulic control module);

- DEM - hydraulic pump drive electric motor;

- RH - load resistance;

- A, V, W - ammeter, voltmeter, wattmeter, respectively;

- HL2 - light indication lamp.

The supply voltage of the electrical system is $220 \mathrm{~V}$, alternating current, $50 \mathrm{~Hz}$. Potentiometric level sensor supply voltage - $12 \mathrm{~V}$, constant current. 
Comparative tests were carried out on an installation with a fiber-reinforced concrete and a metal casing under identical conditions.

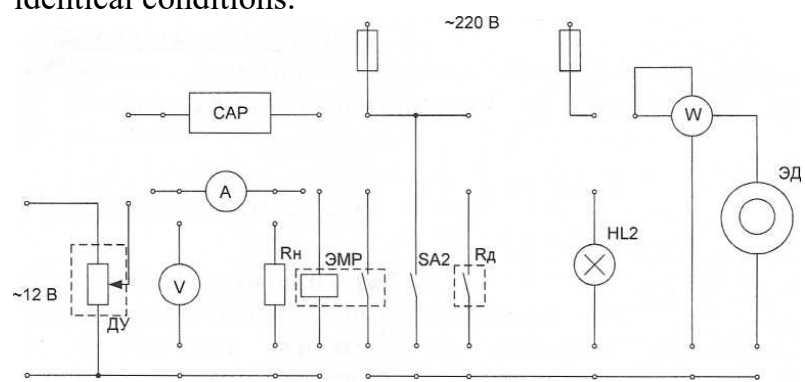

Fig. 3. Electrical diagram of the test bench.

The tests were carried out in the following order:

1. The stand was powered up. For this, the "MAINS" toggle switch on the electrical control module must be set to the upper position. Switch on the pump with toggle switch SA2.

2. Experimental studies were carried out to determine the pump performance. First, acting on the B2 valve, the maximum pressure that the pump develops (according to the $\mathrm{MH}$ manometer) was determined. Then, having divided the range of the pump pressure change into 5 intervals, 6 experiments were carried out. In every experiment, the pressure should be constant. The first experiment began with the minimum pump pressure (that is, with the minimum resistance of the network on which the pump was operating).

Each experiment measured:

1. Pressure at the pump outlet $p_{\mu}$ (according to the manometer);

2. The time $t$ of passing through the flow meter the volume of water $W$ (the volume $W$ must be set, taking, for example, $W=0.01 \mathrm{~m}^{3}\left(10 \mathrm{dm}^{3}\right)$.

3. The power of the $\mathrm{N}_{\mathrm{e}}$ supplied to the electric motor (according to the wattmeter) (when determining the power, the readings of the wattmeter were multiplied by 100 , then the power was obtained in watts). The measurement results were entered in table 2 .

After the completion of the test of the pump with a fiber-reinforced concrete body, the pump with a metal casing was tested in the same way. The measurement results were entered in Table 3.

When processing the research results, the following assumptions were made:

1) the pressure at the pump inlet $\left(p_{6}\right)$ is taken equal to the atmospheric pressure (there are two reasons for this assumption: the presence of a liquid back pressure at the pump inlet, since the water level in the lower tank is higher than the pump location level; relatively low pressure losses in the suction pipeline);

2 ) the vertical coordinates at the pump inlet and outlet are equal, that is, $z_{H}=z_{B}$ (the vertical size of the pump is not taken into account);

3) the average fluid flow rates at the pump inlet and outlet are equal to each other, that is, $V_{H}=V_{B}$.

Thus, the pump flow is equal to:

$$
Q=\frac{W}{t} \cdot \mathrm{m}^{3} / \mathrm{s}
$$

where, $\mathrm{w}$ - volume of water passing through the flow meter, $\mathrm{m}^{3}, \mathrm{t}$ - volume transit time $W$, $\mathrm{s}$.

Pump power:

$$
N=N_{\text {эл }} \cdot \eta_{\text {эл }} \cdot \text { кВт }
$$

where $\eta_{э л}-$ The efficiency of the electric motor (taken constant equal to 0.7 ).

The pump head was determined by the formula:

$$
\mathrm{H}=\frac{P_{\mathrm{H}}}{\rho \cdot g} \cdot \mathrm{m}
$$

where, $P_{\mathrm{H}^{-}}$pump outlet pressure, $\mathrm{MPa}, \rho$ - fluid density, $\kappa \Gamma / \mathrm{M}^{3}, \mathrm{~g}-$ acceleration of gravity

Net pump power:

$$
N_{\Pi}=\mathrm{P}_{\mathrm{H}} \cdot Q \cdot \kappa \mathrm{BT}
$$

where, $P_{\mathrm{H}^{-}}$pump outlet pressure, MPa , $Q$ - pump feed, $\mathrm{m}^{3} / \mathrm{h}$

The pump efficiency is:

$$
\eta=\frac{N_{\Pi}}{N} . \mathrm{kW}
$$

where , $N_{\Pi}$ - net pump power, $\mathrm{kW}, N$ - pump power, $\mathrm{kW}$.

According to the above method, the main parameters of the pump were determined and the results of calculations were entered into tables 2 and 3, and then the operating characteristics of the pump were plotted from the values: $H=f(\mathrm{Q}), N=f(\mathrm{Q}), \eta=f(\mathrm{Q})$ and comparative characteristics of the pump with fiber-reinforced concrete and metal casing.

Table 2. Test results of a pump with a fiber-reinforced concrete body.

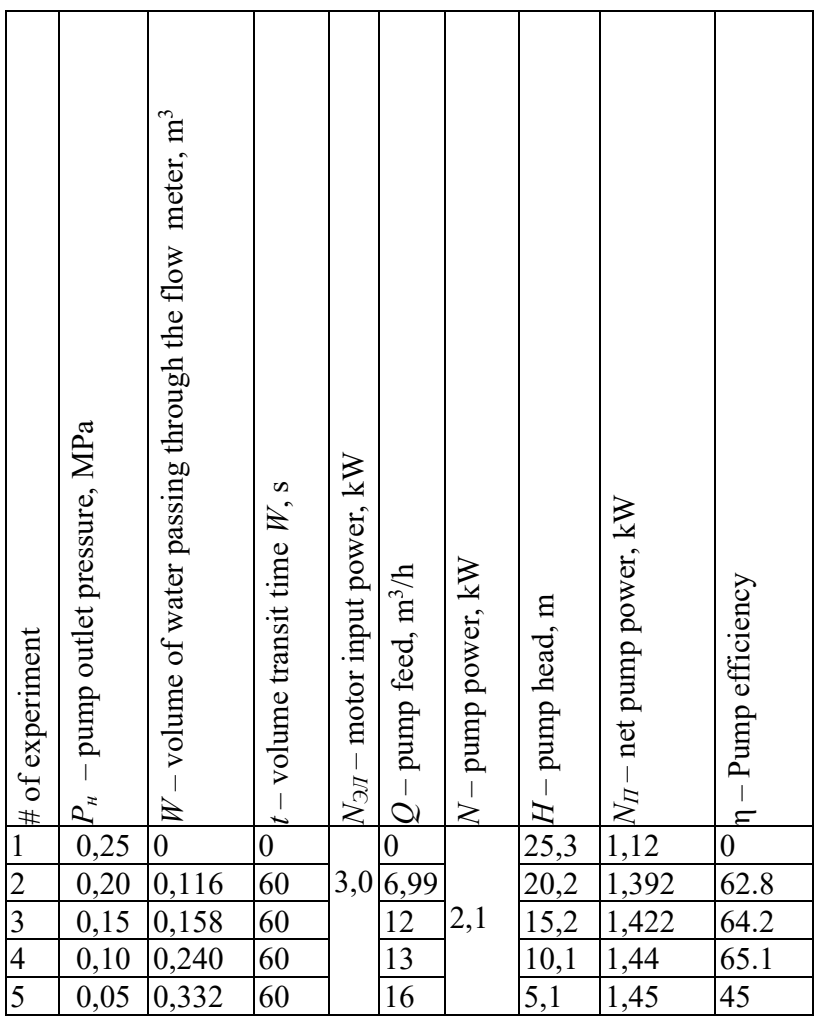

The results of comparative bench tests of a $1 \mathrm{k} 20$ / 30 centrifugal pump with a metal casing and a fiberreinforced concrete casing are shown in Table 4.

The test results show that the parameters of a pump with a fiber-reinforced concrete body are not inferior in characteristics to a pump with a metal body.

\section{Conclusion}

The studies carried out led to the following conclusions: 
Table 3. Test results of a pump with a metal body.

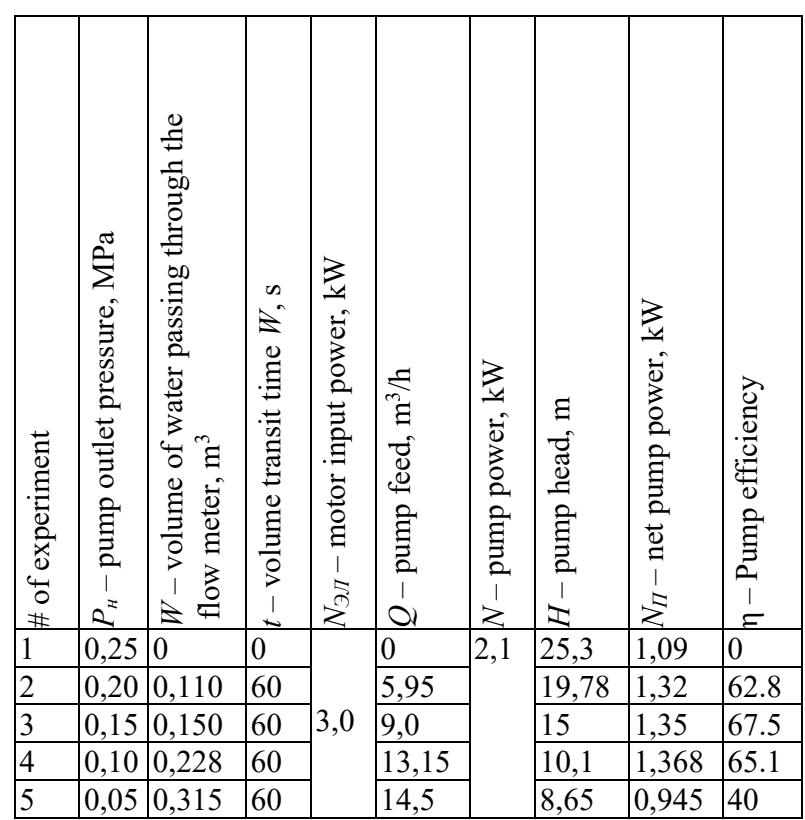

Table 4. Results of bench tests of a centrifugal pump 1k20 / 30

\begin{tabular}{|l|l|l|}
\hline \multirow{2}{*}{ Parameters* } & Values \\
\cline { 2 - 3 } & $\begin{array}{l}\text { Fiber- } \\
\text { reinforced } \\
\text { concrete pump }\end{array}$ & $\begin{array}{l}\text { Metal } \\
\text { body } \\
\text { pump }\end{array}$ \\
\hline Mass M, kg & 20,3 & 30,5 \\
\hline $\begin{array}{l}\text { Volume of water passing } \\
\text { through the flow meter, W, } \\
\mathrm{m}^{3}\end{array}$ & 0,332 & 0,315 \\
\hline $\begin{array}{l}\text { Time of passage of water } \\
\text { volume } W, \mathrm{~s}\end{array}$ & 60 & 60 \\
\hline Feed, $\mathrm{Q}, \mathrm{m}^{3} / \mathrm{h}$ & 19,92 & 18,9 \\
\hline Head, $\mathrm{H}, \mathrm{m}$ & 25,3 & 25,3 \\
\hline Pressure, $\mathrm{p}$ н, $\mathrm{MPa}$ & 0,25 & 0,25 \\
\hline Motor input power, $N_{\text {эл }, \mathrm{kW}}$ & 3,0 & 3,0 \\
\hline Pump power, $N, \mathrm{~kW}$ & 3,0 & 3,0 \\
\hline Net pump power, $N_{П, \mathrm{~kW}}$ & 1,44 & 1,368 \\
\hline Pump efficiency, $\eta$ & 0,685 & 0,651 \\
\hline
\end{tabular}

* For comparison of parameters the maximum values of parameters are selected.

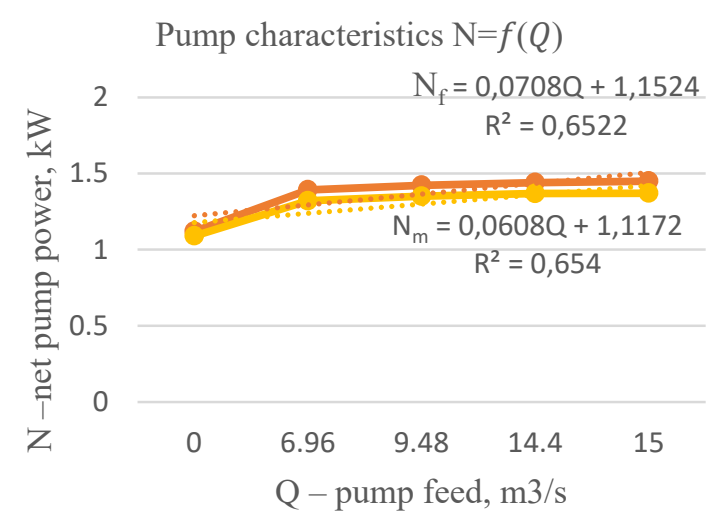

Fig. 4. Characteristics of the $1 \mathrm{k} 20 / 30$ pump: the dependence of the useful power on the supply. $\mathrm{N}=f(Q)$

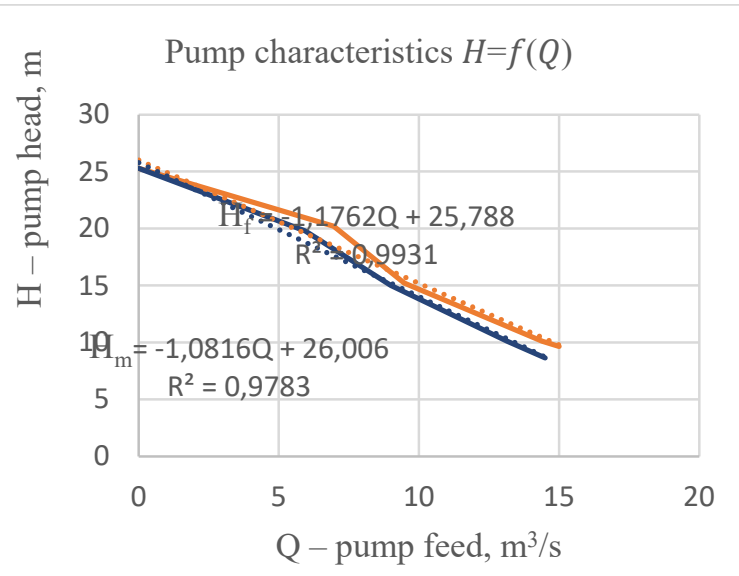

Fig. 5. - Pump characteristics 1k 20/30: the dependence of the head on the flow $\mathrm{H}=f(Q)$.

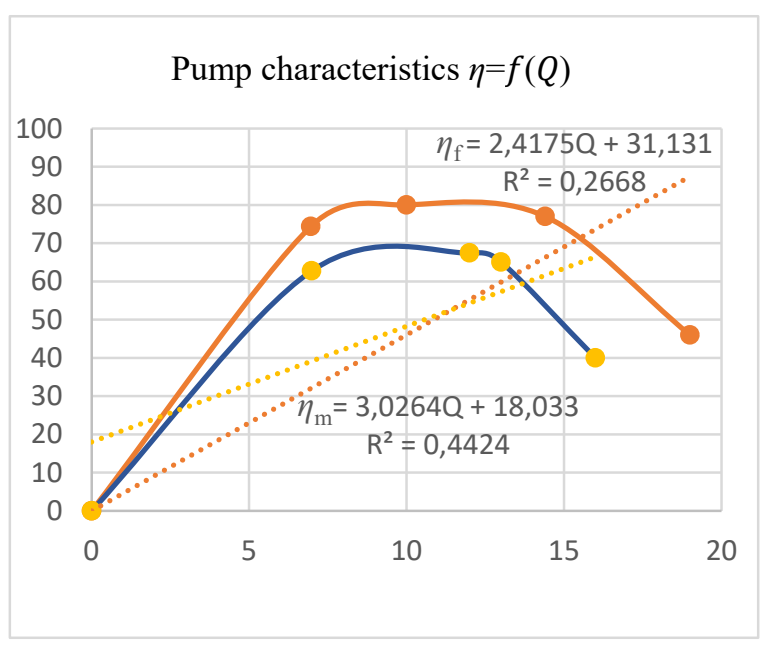

Fig 6. Pump characteristics 1k 20/30: dependence of efficiency on flow $\eta=f(Q)$

1. Fiber concrete in its characteristics fully meets the requirements for materials for the manufacture of centrifugal pump bodies.

2. The proposed method for the selection of the composition of fiber-concrete mixes allows you to obtain optimal mixes that guarantee the necessary physical and mechanical characteristics.

3. The bodies of centrifugal pumps cast from fiberreinforced concrete do not require additional machining and have shown good quality during experimental tests.

4 . The test results showed that samples made of fiberreinforced concrete have a strength $30 \ldots 40 \%$ higher than those of metal, which makes it possible to reduce the thickness of the walls of products by $20 \ldots 25 \%$, which makes it possible to reduce the mass of the pump body by $33-35 \%$.

5. The results of the study showed that when using pump bodies made of fiber-reinforced concrete, the productivity and efficiency of the pump increase by $4-5 \%$ due to the smooth inner surface of the casing.

\section{References}

1. S. V. Klyuev, High-strength fiber-reinforced concrete for industrial and civil construction. 
Engineering and construction journal 8, 61-66 (2012)

2. A. P. Borisyuk, Yu. Yu. Zyatyuk, Investigation of the deformation characteristics of fiber-reinforced concrete with steel fiber. Bulletin of the BelarusianRussian University3 (52), 1-9 (2016)

3. I.N. Shirinzade. Ways to improve the efficiency of fiber-reinforced concrete (2017)

4. R. Fediuk, A. Svintsov, V. Lesovik, A. Pak, R. Timokhin, Designing of special concretes for machine building. Journal of Physics: Conference Series. 1050. 012026 (2018). DOI:10.1088/17426596/1050/1/012026.

5. Krupnik L.A, Yelemessov K.K, Bortebayev S.A, Baskanbayeva D.D., «Studying fiber - reinforced concrete for casting housing parts of pumps»/// Eastern-European Journal of Enterprise Technologies $\begin{array}{llllll}\text { ISSN } & 1729-3774 \quad / / & 6 / 12 & \text { (96) } 2018 .\end{array}$ DOI: https://doi.org/10.15587/17294061.2018.151038.

6. Abdulhadi M. A. (2014) Comparative study of basalt and polypropylene fibers reinforced concrete on compressive and tensile behavior. International Journal of Engineering Trends and Technology (IJETT). Vol. 9. N6. P. 295-300.

7. V.S. Kostyshyn, I.I. Yaremak, P.O. Kurliak. (2019). Creation of object-oriented model of centrifugal pump on the basis of electrohydrodynamic analogy method. Naukovyi Visnyk Natsionalnoho Hirnychoho Universytetu. 6.

8. Pysmennyi, S., Fedko, M., Shvaher, N.,Chukharev, S. (2020). Mining of rich iron ore deposits of complex structure under the conditions of rock pressure development. E3S Web of Conferences, (201), 01022. https://doi.org/10.1051/e3sconf /202020101022.

9. Shvaher,N., Komisarenko,T., Chukharev,S., Panova,S. (2019). Annual production enhancement at deep mining. ). E3S Web of Conferences, (123), art. no. 01043. https://doi.org/10.1051/e3sconf/201912301043.

10. V. Panayotov, M. Panayotova, S. Chukharev, Recent studies on germanium-nanomaterials for LIBs anodes. E3S Web of Conferences 166, 06012 (2020). DOI:https://doi.org/10.1051/e3sconf/202016606012 